Afr. J. Trad. CAM (2006) 3 (2): 27 - 36

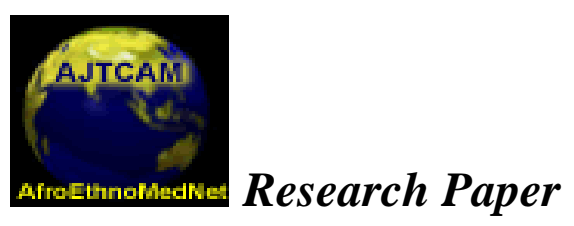

ISSN 0189-6016@2006
Afr. J. Traditional,

\section{Complementary and}

Alternative Medicines

www.africanethnomedicines.net

\title{
CHEMICAL AND PHARMACOLOGICAL EVALUATION OF KARPURA SHILAJIT BHASMA, AN AYURVEDIC DIURETIC FORMULATION
}

\author{
A. M. Saleem ${ }^{\text {a* }}$, V. Gopal ${ }^{\text {a }}$, M. R. M. Rafiullah ${ }^{\text {b }}$, P. Bharathidasan ${ }^{c}$ \\ ${ }^{a}$ Department of Pharmacognosy, C. L. Baid Metha College of Pharmacy, \\ Thorappakkam, Chennai 600 096, India, 1316, School of Pharmacy, College of \\ Medicine, National Taiwan University, Taipei 100, Taiwan R.O.C., ${ }^{\mathrm{b}}$ Faculty of \\ Pharmacy, Hamdard University, New Delhi 110062, India, ${ }^{\mathrm{c} D e p a r t m e n t}$ of Siddha \\ Medicine, Tamil University, Thanjavur, Tamil Nadu 613500, India \\ E-mail address: saleemskma@rediffmail.com, Tel.: +886 0223123456 ext.8392.
}

\begin{abstract}
In this present study, Karpura shilajit bhasma, an Ayurvedic herbo-mineral formulation, currently used in the Ayurvedic clinical practice as a diuretic drug, was investigated chemically and pharmacologically. Content of iron and nitrogen were determined by volumetric analysis and content of calcium, magnesium and aluminium by Inductively Coupled Plasma Atomic Emission Spectrometry (ICP-AES). LD 50 , gross behavioral studies and diuretic activity were evaluated in experimental animals. Calcium was found to be the major element $(24.6044 \% \mathrm{w} / \mathrm{w})$. The $\mathrm{LD}_{50}$ was found to be $4.625 \mathrm{~g} / \mathrm{kg}$ p.o. body weight in mice. Karpura shilajit bhasma produced mild reduction in motor coordination and mild sedation during the first $2 \mathrm{~h}$ after administration at the doses of $500-5000 \mathrm{mg} / \mathrm{kg}$ p.o. in mice. The diuretic activity was found to be significant $(\mathrm{P}<0.01)$ at minimum dose of $200 \mathrm{mg} / \mathrm{kg}$ p.o. in rats and dose dependant up to $1000 \mathrm{mg} / \mathrm{kg}$ p.o. Furthermore, natriuretic effect was found to be significant $(\mathrm{P}<0.01)$, while no significant change was observed on urinary potassium excretion. The present study justified the use of Karpura shilajit bhasma as a diuretic drug. The results of this study could be used as a model data in the standardization of Karpura shilajit bhasma.
\end{abstract}


Afr. J. Trad. CAM (2006) 3 (2): 27 - 36

Key words: Ayurveda; Bhasma; Karpura shilajit bhasma; Shilajit; Diuretic activity

\section{Introduction}

Ayurveda, in its classical texts, describes many proprietary formulations for various renal disorders. Karpura shilajit bhasma is an Ayurvedic formulation described in Ayurvedic literature as a diuretic drug (Anonymous, 1994). As per Ayurvedic medical literature, a bhasma is a substance, which is burnt to ash (Raghunathan, 1976). The method of preparation involves purification of ingredients, mixing them in proper proportions and burning them to ash (Raghunathan, 1976). Swarnabhasma (made from gold), the popular bhasma in Ayurveda, was analyzed for its free radical scavenging activity (Mitra et al., 2002). In our interaction with Ayurvedic physicians towards the standardization of herbs and formulations used in Ayurveda, it was observed that karpura shilajit bhasma has been frequently prescribed by Ayurvedic physicians practicing in southern part of Chennai, India as a diuretic drug for treating various ailments related to renal insufficiency. In the literature survey, it was found that no scientific study has been conducted on this bhasma so far. This directed us to focus on Karpura shilajit bhasma for this study.

The ingredients of Karpura shilajit bhasma are karpura shilajit or white shilajit (1 part), rice wash (water extract of rice [Oryza sativa var. bengalensis G. Watt (Poaceae)] obtained by maceration) (quantity sufficient) and aloe leaf juice [Aloe vera L. Burm. f. (Liliaceae)], (1 part) (Anonymous, 1994). White shilajit is a variety of shilajit and is a rocky exudation from mountains (Nadkarni, 1982). It was reported to contain triterpenes, sterols, aromatic carboxylic acids, ellagic acid, 3,4-benzocoumarins, -amino acids (Ghosal et al., 1976), fulvic acids, humic acids, dibenzopyrones (Ghosal et al., 1993). Although shilajit was reported to exhibit antiulcerogenic activity (Goel et al., 1990), mast cell protecting effect (Bhattacharya et al., 1989), memory and learning enhancing effect (Bhattacharya and Ghosal, 1992), induction of initiation of macrophages to release cytokines (Bhaumik et al., 1993), antidiabetic effect (Bhattacharya, 1995) and antioxidant activity (Bhattacharya and Ananda, 1995) in experimental studies, diuretic activity has not been reported in shilajit. The aloe gel juice has been shown to exhibit stimulation of regeneration of cells in the islets of langerhans including beta cells (Kalinicheva and Shapkina, 1976), antiulcer activity (Gupta et al., 1981), cardiac stimulant activity (Yagi et al., 1982), hypolipidimic activity (Dixit and Joshi, 1983), action against various kidney problems (Sugat et al., 
Afr. J. Trad. CAM (2006) 3 (2): 27 - 36

1983), prevention of extant atheromatous heart disease (Agarwal, 1985), and antidiabetic activity (Yongchaiyudha et al., 1996). Antioxidant and anti-genotoxicity activities have been reported for the water extract of Japanese rice bran (Kiyoka et al., 2004). And, no diuretic activity has been reported for any of the ingredients of Karpura shilajit bhasma. Although the unadulterated components of the formulation have been shown to have biological activity, the bhasma is burnt to ash and it is presumed that these biological properties would be lost. However, the current clinical use of Karpura shilajit bhasma as a diuretic drug prompted us to evaluate the bhasma both chemically and pharmacologically using modern scientific. In this article, the chemical and pharmacological evaluation of Karpura shilajit bhasma is reported.

\section{Materials and Methods}

\section{Karpura shilajit bhasma and Chemicals}

Karpura shilajit bhasma was purchased from a local shop in Chennai, India. All chemicals and reagents used were of analytical grade and purchased from S.D. Fine Chem, Mumbai, India. Government of India certified (Agmark) honey was used as the suspending agent for Karpura shilajit bhasma as prescribed in the Ayurvedic literature (Anonymous, 1994).

\section{Volumetric and UV spectroscopic analysis}

Karpura shilajit bhasma was analyzed for the content of iron by volumetric analysis (Vogel, 1978), organic nitrogen by Kjeldahl method (Bradstreet, 1965) and aloin by UV spectroscopy (Anonymous, 1998). Measurements were made against appropriate standards and blanks prepared under identical conditions. All reagents used were of analytical grade.

\section{Inductively Coupled Plasma-Atomic Emission Spectrometry (ICP-AES)}

The contents of calcium, magnesium and aluminium were determined by Inductively Coupled Plasma Atomic Emission Spectrometry (ICP-AES) by using simultaneous multi-element spectrometer (ARL 3410 ICP, USA) with minitorch (Thompson and Walsh, 1983). $100 \mathrm{mg}$ of karpura shilajit bhasma was dissolved in $1 \mathrm{ml}$ of concentrated Hydrochloric acid $(36 \% \mathrm{w} / \mathrm{v})$ by gentle shaking. The solution was diluted with $25 \mathrm{ml}$ of deionized water and filtered using Whatman no. 1 filter paper. The filtrate was made to 100 
Afr. J. Trad. CAM (2006) 3 (2): 27 - 36

$\mathrm{ml}$ with deionized water and used for analysis.

\section{Animals}

Adult male Wistar rats (150-170 g) (King Institute of Preventive Medicine, Chennai) were maintained in a well-ventilated room with natural day-night cycle in large polypropylene cages. The animals were allowed free access to balanced rodent pellet diet (Poultry Research Station, Tamil Nadu Veterinary and Animal Sciences University, Chennai, India) and tap water. The animals were acclimatized to laboratory conditions for one week before commencement of experiment. The study protocol was approved by the IAEC (Institutional animal ethics committee of CPCSEA, Govt. of India).

\section{Preparation of Karpura shilajit bhasma suspension}

Karpura shilajit bhasma was suspended in honey as prescribed in the Ayurvedic literature (Anonymous, 1994). The volume of honey was adjusted so that it was about 2 $\mathrm{ml} / \mathrm{kg}$ for each animal.

\section{Evaluation of diuretic activity}

The test was performed according to the method of Lipschitz et al., (1943). The animals, fasted and deprived of water for $18 \mathrm{~h}$ prior to the experiment, were divided into eight groups of six rats each. All the animals in eight groups were administered with normal saline $(25 \mathrm{ml} / \mathrm{kg})$ at the starting of the experiment. The first group of animals, serving as control, received only normal saline (25 ml/kg, p.o.); the second group received normal saline ( $25 \mathrm{ml} / \mathrm{kg}$, p.o.) and honey ( $2 \mathrm{ml} / \mathrm{kg}$, p.o.) to study the interaction of honey in diuresis; the third group received furosemide ( $2 \mathrm{mg} / \mathrm{kg}$, p.o.) suspended in gum acacia (1\%) as standard; the groups 4-8 received Karpura shilajit bhasma (arbitrarily selected doses of 10, 100, 200, 500 and $1000 \mathrm{mg} / \mathrm{kg}$ p.o.) suspended in honey. Immediately after dosing, the animals were separately placed in metabolic cages suitable for collection of urine in graduated measuring cylinders cooled with ice. Urine was collected for $5 \mathrm{~h}$ while animals were deprived of food and water. Urine volume was measured. The concentrations of $\mathrm{Na}^{+}$and $\mathrm{K}^{+}$in the urine were determined by flame photometric analysis (James, 1984) by using Mediflame 127 (Systronics, India). 
Afr. J. Trad. CAM (2006) 3 (2): 27 - 36

\section{Determination of $\mathrm{LD}_{50}$ and gross behavioral study}

Arbitrarily selected graded doses (500, 1000, 2000, 3000, 4000 and $5000 \mathrm{mg} / \mathrm{kg}$, p.o.) of Karpura shilajit bhasma suspended in honey were administered to six groups of six albino mice (25-30 g). They were kept in transparent plastic cages at ambient temperature. Mortality was recorded after $24 \mathrm{~h}$ (Litchfield and Wilcoxon, 1949). Gross behavioral study was performed by observing any overt signs after administration of the drug upto $24 \mathrm{~h}$.

\section{Statistical analysis}

The results were given as mean \pm S.E.M. Significance was determined by using the unpaired Student's $t$-test. $P$-value equal to or less than 0.05 was considered as significant.

\section{Results}

\section{Chemical analysis}

Chemical analysis showed the presence of iron $(0.7511 \% \mathrm{w} / \mathrm{w})$, nitrogen $(3.124$ $\% \mathrm{w} / \mathrm{w})$, calcium $(24.6044 \% \mathrm{w} / \mathrm{w})$, magnesium $(0.3666 \% \mathrm{w} / \mathrm{w})$, aluminium $(0.0966$ $\% \mathrm{w} / \mathrm{w})$ and aloin $(1.25 \% \mathrm{w} / \mathrm{w})$ in Karpura shilajit bhasma (Table 1).

Table 1: Chemical analysis of Karpura shilajit bhasma

\begin{tabular}{ll}
\hline Element/Compound & Amount $(\% \mathrm{w} / \mathrm{w})$ \\
\hline Calcium $(\mathrm{Ca})$ & 24.6044 \\
Aluminium $(\mathrm{Al})$ & 0.0966 \\
Magnesium $(\mathrm{Mg})$ & 0.3666 \\
Iron $(\mathrm{Fe})$ & 0.7511 \\
Nitrogen $(\mathrm{N})$ & 3.124 \\
Aloin & 1.25 \\
\hline
\end{tabular}

\section{Diuretic activity}

Karpura shilajit bhasma at the doses of 200,500 and $1000 \mathrm{mg} / \mathrm{kg}$ induced significant $\quad(\mathrm{P}<0.01)$ increase in urine volume, as compared to control group. 
Afr. J. Trad. CAM (2006) 3 (2): 27 - 36

But it was lesser than the diuresis induced by standard drug furosemide. Natriuresis was significantly increased $(P<0.01)$ in rats treated with Karpura shilajit bhasma at the doses of 200, 500 and $1000 \mathrm{mg} / \mathrm{kg}$. Animals treated with furosemide also showed significant $(P<0.01)$ increase in natriuresis. No significant change was observed in urinary excretion of potassium in animals treated with Karpura shilajit bhasma. Control group animals treated with honey and normal saline alone did not produce any significant change in urine volume, sodium and potassium levels in urine (Table 2).

\section{$\mathrm{LD}_{50}$ and gross behavioral study}

The computed $\mathrm{LD}_{50}$ is $4.625 \mathrm{~g} / \mathrm{kg}$ p.o. body weight (data not shown). Karpura shilajit bhasma produced mild reduction in motor coordination and mild sedation, during the first $2 \mathrm{~h}$ after administration, at all the doses administered for $\mathrm{LD}_{50}$.

\section{Discussion}

In the present study, Karpura shilajit bhasma was purchased from a local shop in Chennai, India, since this commercially available formulation was used as a diuretic drug in Ayurvedic clinical practice. Quantification of calcium, aluminium, magnesium and iron in the formulation was carried out since shilajit was reported to contain several minerals (Nadkarni, 1982) and shilajit was one of the major ingredients in the formulation. The chemical analysis revealed the presence of high concentration of calcium $(24.6044 \% \mathrm{w} / \mathrm{w})$ when compared to the concentration of other minerals. Since shilajit was the only herbo-mineral ingredient in this formulation, the high concentration of calcium could be due to shilajit. This implies that the shilajit used in this formulation might have had interacted more with calcium during its formation. As shilajit is the exudation from rocky-mountains and it is composed of herbo-mineral matter (Nadkarni, 1982), the interaction might had resulted in the formation of calcium salts of organic acids. As benzoic acid, hippuric acid, fulvic acid and humic acids were reported in shilajit (Ghosal et al., 1993), the occurrence of calcium salts of these acids in shilajit could be anticipated. The presence of trace quantities of other minerals like aluminium, magnesium and iron could also be from shilajit as it was reported to contain several mineral elements (Nadkarni, 1982). These trace quantities of minerals along with calcium may play an important role in functioning of various enzymes in biological systems. Karpura shilajit bhasma, may therefore, serve as a source of micronutrients as well as a diuretic drug. 
Afr. J. Trad. CAM (2006) 3 (2): $27-36$

Table 2: Diuretic activity of Karpura shilajit bhasma

\begin{tabular}{lllll}
\hline Treatment & Dose & $\begin{array}{c}\text { Urine Volume } \\
(\mathrm{ml})\end{array}$ & $\begin{array}{l}\text { Electrolyte concentration in urine } \\
(\mathrm{ppm})\end{array}$ & \\
\cline { 3 - 5 } & & & Sodium $\left(\mathrm{Na}^{+}\right)$ & Potassium $\left(\mathrm{K}^{+}\right)$ \\
& & & & \\
\hline Normal saline (Control) & $25 \mathrm{ml} / \mathrm{kg}$ & $0.55 \pm 0.05$ & $1896 \pm 23.76$ & $484 \pm 16.43$ \\
Normal saline + honey & $25 \mathrm{ml} / \mathrm{kg}+$ & $0.60 \pm 0.04$ & $1912 \pm 21.24$ & $473 \pm 18.32$ \\
& $2 \mathrm{ml} / \mathrm{kg}$ & & & \\
Furosemide & $2 \mathrm{mg} / \mathrm{kg}$ & $3.45 \pm 0.08^{*}$ & $2324 \pm 27.65^{*}$ & $480 \pm 15.87$ \\
Karpura shilajit bhasma & $10 \mathrm{mg} / \mathrm{kg}$ & $0.62 \pm 0.06$ & $1887 \pm 25.34$ & $475 \pm 14.97$ \\
suspended in honey & & & & \\
& $100 \mathrm{mg} / \mathrm{kg}$ & $0.74 \pm 0.03$ & $1940 \pm 26.83$ & $481 \pm 17.63$ \\
& $200 \mathrm{mg} / \mathrm{kg}$ & $1.23 \pm 0.01^{*}$ & $2050 \pm 25.43^{*}$ & $478 \pm 16.56$ \\
& $500 \mathrm{mg} / \mathrm{kg}$ & $2.19 \pm 0.06^{*}$ & $2245 \pm 23.61^{*}$ & $482 \pm 15.95$ \\
& $1000 \mathrm{mg} / \mathrm{kg}$ & $3.12 \pm 0.08^{*}$ & $2434 \pm 24.95^{*}$ & $479 \pm 16.24$ \\
\hline
\end{tabular}

$\mathrm{n}=6$.

Values are mean \pm S.E.M.

$* \mathrm{P}<0.01$.

The amount of organic nitrogen $(3.124 \% \mathrm{w} / \mathrm{w})$ indicates that considerable amount of organic constituents are present in the formulation even after incineration at elevated temperatures during its manufacture. The manufacturing of bhasma involves incineration and the ingredients are converted into ash (Raghunathan, 1976). But comparatively lower amount of aloin in relation to aloe juice's percentage $(\leq 50 \%)$ in the formulation suggested that major part of aloin could have undergone chemical degradation at the elevated temperatures of incineration, which was estimated to be around $1000{ }^{\circ} \mathrm{C}$ (Mitra et al., 2002), during the manufacturing process.

The diuretic activity results showed that Karpura shilajit bhasma produced significant and dose dependant increase in total urine output $(P<0.01)$ over a period of $5 \mathrm{~h}$ and was comparable to that of furosemide. It also increased the excretion of sodium significantly. However, no significant increase was observed for potassium excretion. The dosage for diuretic activity was selected arbitrarily and the maximum dosage (1000 $\mathrm{mg} / \mathrm{kg}$ ) was set at a value slightly lower than the value of $1 / 4^{\text {th }}$ of $\operatorname{LD}_{50}(4.625 \mathrm{~g} / \mathrm{kg})$.

Since honey was prescribed as a vehicle for Karpura shilajit bhasma in Ayurveda 
(Anonymous, 1994), Karpura shilajit bhasma was administered as a suspension in honey and a solvent control group, administered with normal saline and honey was employed to study the effect of honey on diuresis in this present study. Drug administration was done by oral route, since it was recommended in Ayurveda (Anonymous, 1994). The dosage for honey was selected arbitrarily. The results showed that honey at the dose of $2 \mathrm{ml} / \mathrm{kg}$ body weight p.o. did not produce any diuresis in rats.

No diuretic activity was reported in shilajit, aloe juice and rice wash. And also, the chemical composition and nature of compounds in the bhasmas after incineration at elevated temperatures have not been reported. To our knowledge, no relationship could be found from the literature between the presence of the chemicals analyzed in this study such as high calcium content and diuretic activity. However, the amount of organic nitrogen $(3.124 \% \mathrm{w} / \mathrm{w})$ indicates that considerable amount of organic constituents are present in the formulation even after incineration at elevated temperatures during its manufacture. Hence the compound or compounds responsible for the diuretic activity of Karpura shilajit bhasma could be an organic compound either produced or modified in a reaction which might have happened at the elevated temperatures of incineration or remained as such from its source. Hence the active compound responsible for diuretic activity of Karpura shilajit bhasma needs to be isolated for further study preferably in a activity guided isolation method.

In the gross behavioral study, Karpura shilajit bhasma produced mild reduction in motor coordination and mild sedation during the first $2 \mathrm{~h}$ after administration (data not shown). This warrants detailed evaluation of toxicity of Karpura shilajit bhasma. Further studies are in process to assess the possible adverse reactions and toxicity in animal models.

In conclusion, this study demonstrated the significant diuretic activity of Karpura shilajit bhasma and justified its current clinical use as a diuretic drug in Ayurveda. However, its safety and adverse reactions should be evaluated to validate its therapeutic potential. The results of this study could serve as a dataset in the standardization of Karpura shilajit bhasma.

\section{References}

1. Agarwal, G. P. (1985). Prevention of atheromatous heart disease. Angiology 36: 485-492.

2. Anonymous, (1994). Vaidya Yoga Ratnavali (Formulary of Ayurvedic Medicine), 
Afr. J. Trad. CAM (2006) 3 (2): $27-36$

IMPCOPS, Chennai, India, pp. 61-92.

3. Anonymous, (1998). Indian Herbal Pharmacopoeia, vol. I, First edition, Joint Publication of Regional Research Lab, Jammu and Tawi, Indian Drug Manufacturers Association, Mumbai, India, pp. 11-17.

4. Bhattacharya, S.K. and Ananda P.S., (1995). Effects of shilajit on biogenic free radicals. Phytother Res 9: 56-59.

5. Bhattacharya, S.K. and Ghosal, S., (1992). Effects of shilajit on rat brain monamines. Phytother Res 6: 1163-1164.

6. Bhattacharya, S.K., (1995). Activity of shilajit on alloxan-induced hyperglycaemia in rats. Fitoterapia 116: 328-332.

7. Bhattacharya, S. K., Dasgupta, G., Bhaduri, J., Mukhopadhyay, M., Goel, R.K. and Dey, R., (1989). Mast cell protecting effects of shilajit and its constituents. Phytother Res 3: 249-252.

8. Bhaumik, S., Chattopadhyay, S. and Ghosal, S., (1993). Effect of shilajit on mouse peritoneal macrophages. Phytother Res 7: 425-427.

9. Bradstreet, R.B., (1965). The Kjeldahl Method for Organic Nitrogen. Academic Press Inc., New York, USA, pp. 23-24.

10. Dixit, V.P. and Joshi, S., (1983). Effect of Aloe barbadensis and clofibrate on serum lipids in triniton-induced hyperlipidimia in presbyter entellus monkeys. Indian J Med Res 78: 417-421.

11. Ghosal, S., Lal, J., Kanth, R. and Kumar, Y., (1993). Similarities in the core structures of shilajit and soil humus. Soil Biol Biochem 25: 377-381.

12. Ghosal, S., Reddy, J.P. and Lal, V.K., (1976). Shilajit I: chemical constituents. J Pharm Sciences 65: 772-773.

13. Goel, R.K., Banerjee, R.S. and Acharya, S. B., (1990). Antiulcerogenic and anti-inflammatory studies with shilajit. J. Ethnopharmacol. 29: 95-103.

14. Gupta, M.B., Nath, R., Gupta, G.P. and Bhargava, K.P., (1981). Antiulcer activity of some plant triterpenoids. Indian J Med Res 73: 649-652.

15. James, W.M., (1984). Pharmaceutical Analysis (Modern Methods)-Part B. Marcel Dekker Inc.,USA, pp.385-388.

16. Kalinicheva, N.V. and Shapkina, A.V., (1976). Stimulation of the regeneration of the insular epithelium of the pancreas by some drugs. Trudy Leningradskogo Sanitarno-gigienicheskogo Meditsinskogo Institute 112: 58-64.

17. Kiyoka, H.O., Keiko K., Kanako A., Akiko H., Chie S., Norie M. and Yasuji O., (2004). Potent antioxidative and antigenotoxic activity in aqueous extract of Japanese rice bran - association with peroxidase activity. Phytother Res 18:. 
Afr. J. Trad. CAM (2006) 3 (2): $27-36$

628-633

18. Lipschitz, W.L., Hadidin, Z. and Kerpesar, A., (1943). Bioassay of diuretics. J Pharmacol Experimental Therapeutics 79: 97-110.

19. Litchfield, J. T. and Wilcoxon, F. (1949). A simplified method for evaluating dose effect experiments. J. Pharmacol. 96: 99-113.

20. Mitra, A., Chakraborty, S., Auddy, B., Tripathi, P., Sen, S., Saha, A. V., Mukherjee, B., (2002). Evaluation of chemical constituents and free-radical scavenging activity of Swarnabhasma (gold ash), an ayurvedic drug. J. Ethnopharmacol. 80: 147-153.

21. Nadkarni K.M., (1982). Indian Materia Medica. vol. II, Popular Prakashan Pvt. Ltd., Bombay, India, pp. 23-32.

22. Raghunathan, K., (1976). Pharmacopoeial standards for Ayurvedic formulations. Central Council for Research in Indian Medicine and Homoeopathy, New Delhi, India, pp. 42.

23. Sugat, T. and Hirata, T., (1983). The efficacy of the aloe plants chemical constituents and biological activities. Cosmetics Toiletries 98: 105-108.

24. Thompson, M. and Walsh, J.N., (1983). A handbook of inductively coupled plasma spectrometry. Blackie and Son Ltd., London, England, pp. 16-36.

25. Vogel, A.I., (1978). Vogel's Textbook of Quantitative Inorganic Analysis. ed. IV, Longman Group Ltd., England, pp. 742.

26. Yagi, A., Shibata, S., Nishioka, I., Iwadre, S., Ishida, Y., (1982). Cardiac stimulant action of constituents of Aloe saponaria. J Pharm Sci. 71: 739-741.

27. Yongchaiyudha, S., Rungpitarangsi, V., Bunyapraphatsara, N., Chokechaijaroenporn, O., (1996). Antidiabetic activity of Aloe vera L. juice I. Clinical trial in new cases of diabetes mellitus. Phytomedicine 3: 241-243. 